Departamento de Historia Universidad de Santiago de Chile

Revista de Historia Social

y de las Mentalidades

Volumen 24, $\mathrm{N}^{\circ} 1,2020: 381-412$

Issn On Line: 0719-4749

\title{
NOTAS ETNOGRÁFICAS PARA EL DESARROLLO DE ARCHIVOS BAJO LA MIRADA DEL PATRIMONIO CRÍTICO*
}

\author{
ETHNOGRAPHIC NOTES FOR THE DEVELOPMENT OF FILES \\ UNDER THE LOOK OF CRITICAL HERITAGE
}

\author{
DR. PABLO ANDRADE BLANCO** \\ Universidad de Santiago de Chile \\ Santiago, Chile \\ Email: pablo.andrade@usach.cl \\ Id-ORCID: 0000-0003-0648-2664 \\ MG. MARÍA ANGÉLICA MARTÍNEZ P. \\ Pontificia Universidad Católica de Chile \\ Santiago, Chile \\ Email: amartinezpo@uc.cl \\ Id-ORCID: 0000-0002-0994-6048
}

\begin{abstract}
RESUMEN
Este artículo analiza tres diferentes archivos y propone, desde una investigación aplicada, visualizar las principales problemáticas a las que se enfrentan en los procesos de rescate, documentación y conservación, y, observar el concepto de puesta en valor de los bienes culturales conservados por estas instituciones como un eje escindido del campo técnico que caracteriza la labor archivística, definiéndose por ahora, como un ejercicio vincular potencial o intermitente. Se propone una reflexión
\end{abstract}

\begin{abstract}
This article analyzes three different archives and proposes, from an applied research, to visualize the main problems that the rescue, documentation and conservation processes face, and to observe the concept of enhancement of the cultural assets conserved by these institutions as a split axis of the technical field that characterizes archival work, defining itself for now as a potential or intermittent linking exercise. In summary, a reflection is proposed that urges the archives to
\end{abstract}

* Recibido: 20 de febrero de 2020. Aprobado: 16 de mayo de 2020.

** Artículo científico. Este artículo corresponde al proceso de investigación etnográfica aplicada en diversos archivos, bajo una mirada transdisciplinar, por parte de ambos autores. Los antecedentes presentados en este son parte de asesorías y trabajos empíricos en diversos archivos de la región metropolitana que permitieron generar una unidad de análisis etnográfico para su investigación conjunta. 
que insta a los archivos a situarse no solo como un repositorio de documentos que surgen en un tiempo anterior para hablar de ese pasado, sino también a entenderlos como centros complejos de memorias que cobran sentido en presente cuando ponen a la comunidad como eje de su labor.

Palabras clave: Archivo; patrimonio cultural; puesta en valor; comunidad position themselves not only as a repository of documents that arose in an earlier time to talk about that past, but to understand them as complex centers of memories that make sense in the present when they put the center of its work to the community.

Keyword: Archive; Cultural Heritage; Valuing; Community

Cómo citar: Andrade, Pablo y María A. Martínez P. (2020). "Notas etnográficas para el desarrollo de archivos bajo la mirada del patrimonio crítico". Revista Historia Social y de las Mentalidades, 24(1), 381412. DOI: $10.35588 /$ rhsm.v24i1.4366.

\section{INTRODUCCIÓN}

Estas Rupturas-desplazamientos están indicando un avance estratégico al contextualizar lo que se produce en los medios por relación a los demás espacios de lo cotidiano. Me refiero a algunos espacios clave: el barrio como nuevo lugar de lucha por la identidad de los grupos populares, la calle como lugar de una violencia particular en el circuito inseguridad-represión y las diferentes formas de presencia de lo policial, los mercados y su peculiar forma entre memoria popular e imaginario mercantil, el espacio escolar y familiar. (Martín-Barbero 112)

¿Cómo se relacionan los acervos patrimoniales ${ }^{1}$ de $\operatorname{los} \operatorname{archivos}^{2}$ con sus comunidades, y, desde dónde surgen estas relaciones? ¿Están sesgados por su comunidad de origen aspirando, generalmente, a establecer vínculos con el mundo de la investigación académica? ¿Priorizan los aspectos de conservación olvidando la activación y valoración de sus bienes, lo que presupone desarrollar el sentido público y democrático implícito en su construcción?

Comenzar con esta cita como con estas preguntas, tiene por objeto decantar una reflexión profunda sobre el modo en que nos relacionamos con fondos y

1 Entendemos como patrimonial la asignación de valores de un colectivo a bienes culturales tales como documentos, objetos, prácticas culturales y saberes por sobre otros bienes culturales.

2 Entendemos por archivo el acervo patrimonial acopiado por distintos centros de documentación, centros de investigación y programas, que centran su trabajo y su misión en el resguardo de la memoria de sus ámbitos de especialización. 
colecciones contenidos en archivos pertenecientes al mundo público y privado: Los Archivos de la Fundación Miguel Enríquez, el Centro de Documentación Fundación Salvador Allende y el Programa de Investigación y Archivos de la Escena Teatral de la Escuela de Teatro UC. El artículo reúne experiencias asociadas al trabajo realizado durante el año 2019, a las cuales damos forma de notas de campo para componer un ejercicio etnográfico que, a través de la sistematización de la información, permita construir un estudio ex post en donde los tres relatos generen una única unidad de análisis.

Los casos seleccionados transitan por distintas etapas de implementación, lo que nos permite crear una relación de estadios en la gestión de un archivo desde su inicio a su consolidación al entenderlos como una misma unidad etnográfica: el vínculo con el primero está asociado a su nacimiento, al momento constitutivo que define sus intereses y lineamientos. El segundo caso se desarrolla a partir de un estudio evaluativo de su gestión, posibilitando distinguir las falencias de origen y los caminos eventuales de conservación y valoración de sus colecciones. Y, por último, el tercero propone quebrar el espacio de soledad implícito a la labor, a través de la creación de un ejercicio de activación patrimonial de una de sus colecciones, otorgándole aquel sentido público y democrático de acceso.

Esta definición metodológica nos permite desarrollar, a modo de hipótesis, el siguiente enunciado: el sistema archivístico del grupo estudiado se ha focalizado en la conservación, registro y documentación de sus fondos y colecciones, pues contiene bienes culturales de valor para las futuras generaciones, pero ha dejado en segundo plano los procesos de acceso y valoración patrimonial de sus acervos que son, finalmente, los activadores del rol público que estos están llamados a cumplir ${ }^{3} \mathrm{y}$, por tanto, la conexión con sus comunidades en presente.

Las experiencias convocadas para el desarrollo de este artículo se modelan bajo una aproximación etnográfica en tanto la relación que sostienen estos centros de documentación y las comunidades, poniendo el acento de la discusión en el valor del archivo y la activación de su patrimonio, y buscando contribuir con un punto de vista que analice hasta qué punto se han sobredimensionado los aspectos técnicos de la archivística para que estos medios se hayan vuelto un fin en sí mismos. Proponemos desarrollar una mirada crítica a su gestión y ofrecer una conclusión que permita estimular la verdadera conexión de estos documentos de memoria con sus comunidades.

3 La valoración o activación patrimonial de los archivos, en palabras de L. Prats, apunta a la acción que permite la apropiación de sus significados y valores. 


\section{LA URDIMBRE ETNOGRÁFICA}

El estudio se ha generado a partir de una investigación aplicada basada en la evaluación etnográfica de los Archivos de la Fundación Miguel Enríquez, Centro de Documentación Fundación Salvador Allende y Programa de Investigación y Archivos de la Escena Teatral de la Escuela de Teatro UC definiendo tres momentos de análisis en la vinculación con los archivos mencionados, comprendiendo que cada caso configura una única unidad. ${ }^{4}$

- Experiencia Constitutiva: definición de los lineamientos para el desarrollo del Archivo de la Fundación Miguel Enríquez.

- Experiencia Evaluativa: aplicación de un modelo de evaluación cualitativa del acervo y estado del Centro de Documentación de la Fundación Salvador Allende.

- Experiencia Valorativa: desarrollo de estrategias de valoración y apropiación comunitaria de los fondos de teatros universitarios conservados por el Programa de Investigación y Archivos de la Escena Teatral UC.

Al agrupar estos tres casos de análisis en una misma unidad, identificamos sus acervos vinculados al soporte de la memoria y su aspecto representacional y relacional para con las comunidades con las que conviven (Andrade \& Mellado, Museología Mestiza. Dinamicidad Teórico Metodológica para enfrentar museos plurinacionales y poscoloniales, 2020). Con ello, situamos la discusión etnográfica bajo una perspectiva teórica transdisciplinar ${ }^{5}$ que nos permite enfocar nuevos aspectos del trabajo desarrollado por los centros, pensando de qué manera podemos imbricar la trama teórico-metodológica de otras disciplinas e incorporar nuevas aristas en la discusión evaluativa, pero también, a su gestión.

\subsection{Los archivos como plataformas de dinámicas sociales}

En primer lugar, debemos situarnos desde la unidad de análisis definida en el corpus seleccionado. En este sentido, buscamos comprender el ejercicio

$4 \quad$ Las técnicas de análisis empleadas para los casos fueron observación participante para los tres casos y entrevistas en profundidad para el segundo caso. En este sentido, la vinculación de los investigadores fue en el desarrollo de las tres experiencias como parte de los equipos en su diseño y orientación. Es por esto que cada una refleja una unidad de análisis distinta que, en el ejercicio etnográfico y conformación de su relato, se han unido para aproximarnos a una reflexión crítica de los archivos.

5 Nos referimos a los aspectos transversales teóricos que aportan diversas disciplinas al método etnográfico para el proceso de observación e interpretación. 
etnográfico como un proceso asociado a la descripción densa, tal y como lo menciona Clifford Geertz (2000), quien plantea que para acercarnos a los archivos que han emergido en estos últimos 30 años, debemos generar una aproximación ligada a un fenómeno cultural, entendiendo cómo estos se incorporan a una dinámica social contemporánea y contingente, y a su relevancia en el país que los origina, y no bajo un prisma de análisis institucional.

Al retomar las ideas Geertz, hablamos de la cultura como trama simbólica que se entreteje y perpetúa a través de estrategias y acciones comunicativas relacionadas con los grupos sociales a los que pertenece.

Considerar las dimensiones simbólicas de la acción social -arte, religión, ideología, ciencia, ley, moral, sentido común- no es apartarse de los problemas existenciales de la vida para ir a parar a algún ámbito empírico de formas desprovistas de emoción; por el contrario, es sumergirse en medio de tales problemas. La vocación esencial de la antropología interpretativa no es dar respuestas a nuestras preguntas más profundas, sino darnos acceso a respuestas dadas por otros, que guardan otras ovejas en otros valles, y así permitirnos incluirlas en el registro consultable de lo que ha dicho el hombre. (Geertz 40)

Lo planteado por Geertz en el párrafo anterior, nos proporciona un enfoque que permite desentrañar la relación de los archivos en una comunidad mayor y no únicamente vinculada con la que le dio origen. En este sentido, la evaluación etnográfica de archivos patrimoniales busca profundizar, en la idea de las relaciones y articulación de estos y su capacidad de contribuir al conocimiento en conjunto con la sociedad.

Si tomamos como punto de partida la definición de International Council on Archives (ICA), que plantea a los archivos como documentos creados por individuos $\mathrm{u}$ organizaciones para el desarrollo de sus actividades y que, con el tiempo, serán el acceso a eventos ocurridos en el pasado, apelando, desde una multiplicidad de soportes, a la memoria de las naciones y sus sociedades, podemos desprender que el fin último de estos se asocia al conocimiento de nuestro pasado que, a partir de testimonios que hemos impreso y que permiten relatar acontecimientos vinculados a hechos históricos, asienta la memoria colectiva y por tanto la identidad y la democracia.

Esto dirige la atención a la configuración de los enunciados que poseen los diversos archivos etnografiados, donde lo simbólico no solo se desprende de los bienes custodiados por las diferentes instituciones, sino de las construcciones 
discursivas que les dan sentido a estas. Si apelamos a la mirada foucaultiana definida en La arqueología del saber, habría entonces que describir los enunciados de dichas organizaciones en su contexto de origen, pero, desde una mirada del presente y en vinculación con los actuales colectivos sociales y políticos (Foucault 13).

Por otra parte, si tomamos en cuenta desde nuestra perspectiva una orientación clásica de la archivística para los procesos de registro y valorización de los archivos, nos encontramos con el siguiente esquema que representa una secuencia lineal y sistémica del ingreso de documentación a un "archivo genérico" y describe, de manera somera, el tratamiento de que le dará un valor en relación con otros documentos:

Ilustración 1: Procesos de registro y documentación.

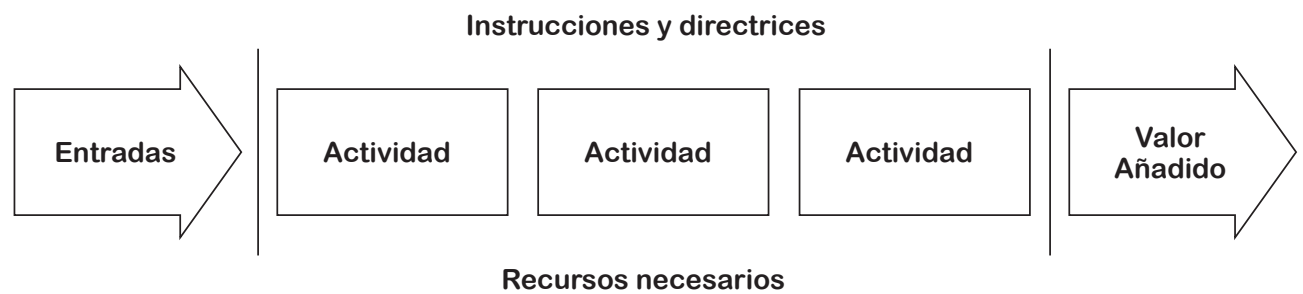

Fuente: Hernández y Moro.

Sin embargo, la aproximación desde una mirada etnográfica fenomenológica busca establecer estas situaciones de valoración realizadas por diversos grupos y personas y en relación con diversas comunidades, incorporando e implementando, en esta unidad de análisis etnográfico, múltiples miradas disciplinares, que permitan profundizar en los enunciados o tramas simbólicas de los archivos analizados.

En suma, lo que necesitamos es buscar relaciones sistemáticas entre diversos fenómenos, no identidades sustantivas entre fenómenos similares. Y para hacerlo con alguna efectividad, debemos reemplazar la concepción "estratigráfica" de las relaciones que guarden entre sí los varios aspectos de la existencia humana por una concepción sintética, es decir, una concepción en la cual factores biológicos, psicológicos, sociológicos y culturales puedan tratarse como variables dentro de sistemas unitarios de análisis. Establecer un lenguaje común en las ciencias sociales no es una cuestión de coordinar meramente 
terminologías o, lo que es aún peor, de acuñar nuevas terminologías artificiales; tampoco es una cuestión de imponer una sola serie de categorías a todo el dominio. Se trata de integrar diferentes tipos de teorías y conceptos de manera tal que uno pueda formular proposiciones significativas que abarquen conclusiones ahora confinadas en campos de estudios separados. (Geertz 51)

Ilustración 2: Representación del proceso de valoración.


Fuente: Hernández y Moro 29.

Estas etapas en la cadena de valoración permitirían a los archivos definir de manera clara los procesos de selección, descartes y disposición final de los documentos (International Council on Archives 1), siendo este uno de los mayores retos que existen en la gestión documental.

...que el gran reto de las gestiones documentales, tradicionales o electrónicas sea la valoración o evaluación documental que ha de partir de una correcta identificación que permita reconocer los valores primarios y secundarios de los documentos que nos lleven a su selección, mejor a priori que a posteriori, para poder concluir ¿qué hay que eliminar? y ¿qué hay que conservar? para el futuro. (Sierra 1)

Desde esta perspectiva, la estrategia de registro y documentación proporciona un mecanismo que permite la sistemática reducción de la masa documental mediante la utilización de un conjunto de criterios que toma en cuenta la naturaleza específica de la información moderna registrada, y que obliga a realizar un trabajo cuidadoso en el que es necesario emplear conocimientos particulares para la representatividad e historicidad de las fuentes documentales. (Rivas 6)

Para Brown, el concepto de creador de documentos es concebido como una expresión o una declaración de mensajes que se encuentran enraizados en los documentos, para descubrirlos, el archivista puede apropiarse de las teorías de la hermenéutica de análisis de texto y 
de discurso, aplicados al contexto de los documentos producidos por las instituciones en el curso de sus actividades funcionales; es decir, observando al creador dentro del contexto de su formación de discurso. Señala que el entendimiento de Michel Foucault del discurso es altamente instructivo, haciendo algunas sutiles conexiones entre la ontología del texto y la arqueología de la información del archivo; así como, la potencial adaptación de la teoría hermenéutica del texto de Paul Ricoeur, en su conciliación de la interpretación del texto basada en la lectura de su contenido narrativo y la objetivación de su contexto, a través de un entendimiento de su estructura narrativa discursiva. (Rivas 7)

En este aspecto, la etnografía, como técnica cualitativa de análisis busca identificar la relación de los archivos citados anteriormente con sus grupos o colectivos de origen, así como con otros colectivos de una trama mayor, y también, las estrategias de valoración planteadas e implementadas por estos. En este contexto, nos aproximamos a la categorización empleada por Taylor:

El nombre que le pondría sería el Archivo y el repertorio. Una de las principales lecturas equívocas de esta obra, a mi parecer, es que el "archivo" y el repertorio existan de manera binaria, uno opuesto al otro. El archivo, escribí, "Existe en forma de documentos, mapas, textos literarios, cartas, restos arqueológicos, huesos, videos, películas, discos compactos, todos esos artículos supuestamente resistentes al cambio. El repertorio requiere presencia, la gente participa en la producción y reproducción de saber al estar allí y ser parte de esa transmisión. (Taylor 17)

\section{NOTAS ETNOGRÁFICAS}

\subsection{Memoria $1 .{ }^{6}$ La constitución de un archivo}

¿Qué determina la necesidad de crear un archivo? ¿Qué lleva a un colectivo a tomar esta decisión? Existe, pareciera, una necesidad propia de conservar y traspasar nuestro legado a futuras generaciones, legado que, muchas veces, atañe

6 El concepto de memoria es utilizado en este horizonte etnográfico como el ejercicio práctico y, también, como el sentido último de los archivos, que es el de resguardar memorias individuales y colectivas expresadas en documentos que constituyen su soporte. 
a una microhistoria, a un reducido espacio delimitado por nuestras acciones personales. Sin embargo, ¿qué sucede cuando hablamos de una historia colectiva, de una historia asociada a otros actores, a otros sujetos, a colectivos que tienen una relación con la historia política de un lugar, de un territorio o de un país?

Esta descripción etnográfica habla de las percepciones del valor colectivo en estos archivos, de la relación documental, de la relación objetual de estos, particularmente de la documentación custodiada por la Fundación Miguel Enríquez (FME), puesto que el legado que configura este archivo proviene primeramente de fuente directa y traza luego un camino que abre el espectro documental al Movimiento de Izquierda Revolucionaria y al periodo históricopolítico que lo determina.

Con la creación de la Fundación Miguel Enríquez, en el año 2014, comienza el proyecto de generar un archivo histórico del Movimiento de Izquierda Revolucionaria. Para ello, Carmen Castillo, pareja de Miguel Enríquez al momento de su muerte, entrega al Presidente de Fundación, Andrés Pascal Allende, varias cajas con distintas tipologías de materiales que el Secretario General del MIR había guardado en un barretín ${ }^{7}$ en la casa de la familia Castillo Velasco. Luego de este gesto, otros exmilitantes del MIR ceden diversos archivos documentales en variados soportes materiales que habían conservado durante décadas. Estos objetos, documentos, y materiales en general, formaron parte de su memoria personal, de una historia cercenada, que encuentra su cabida en la asociación con otros archivos.

Frente al acopio de estos materiales (revistas, panfletos, documentos, instructivos, fotografías, casetes, entre otros), surge la necesidad de definir parámetros que permitan identificar aspectos organizativos de la información como lo son la identificación de hitos históricos del MIR, organización política revolucionaria de Chile que se funda en la confluencia de distintas organizaciones y grupos de izquierda en agosto de 1965. En su declaración de principios señala que "se organiza para ser la vanguardia marxista-leninista de la clase obrera y capas oprimidas de Chile que buscan la emancipación nacional y social." (Movimiento de Izquierda Revolucionaria). Continúa indicando que,

la finalidad del MIR es el derrocamiento del sistema capitalista y su reemplazo por un gobierno de obreros y campesinos, dirigidos por los órganos del poder proletario, cuya tarea será construir el socialismo y extinguir gradualmente el Estado hasta llegar a la sociedad sin

El barretín es un agujero, similar al tatú, que se utiliza para ocultar objetos. 
clases. La destrucción del capitalismo implica un enfrentamiento revolucionario de las clases antagónicas. (Movimiento de Izquierda Revolucionaria)

El MIR sostiene que la única clase social capaz de realizar las tareas democráticas combinadas con las socialistas era el proletariado, a la cabeza de los campesinos y clase media empobrecida: liberación nacional, reforma agraria, expulsión del imperialismo, socialización de sectores estratégicos, control estatal del comercio exterior e interior, etcétera.

Durante el gobierno de la Unidad Popular, el MIR impulsa la organización de distintos sectores sociales a través de la conformación de los denominados frentes intermedios: el Frente de Trabajadores Revolucionarios FTR; el Movimiento de Campesinos Revolucionarios MCR; el Frente de Estudiantes Revolucionarios FER; y, el Movimiento de Pobladores Revolucionarios MPR. Junto a ellos y otras organizaciones políticas de izquierda, da alce y desarrollo a la conformación del poder popular en la organización de distintos cordones industriales (organización de los trabajadores/as de un sector industrial determinado) y de comandos comunales (espacio que convocaba a todas las organizaciones funcionales y políticas de un territorio determinado).

Posterior al golpe de Estado de 1973, promociona una política de "no asilo" con el objeto de conformar la resistencia popular a la dictadura cívico militar. Después de varios golpes represivos, de la muerte en combate de su Secretario General, Miguel Enríquez, y de la caída de parte importante de su dirección política, impulsa lo que con los años se denomina Plan 78 u Operación Retorno, que consiste en el retorno clandestino de sus militantes desde el exilio. La represión, la crisis de la deuda externa, y la movilización popular creciente contra la dictadura militar, entre otros fenómenos, abren una fuerte discusión al interior de la organización sobre su táctica y estrategia, frente a lo cual se propone la realización de su IV Congreso Partidario a mediados de los años 80 (1986-1987). Sin embargo, en medio del proceso de discusión, las células internas se terminan separando orgánicamente. Estas divisiones debilitan a la organización y, hacia 1994, el movimiento se disuelve.

Si bien la información dispuesta en distintas publicaciones nos señala un camino de inicio para abordar la diversidad de documentos existentes hoy en el archivo de la FME, la relación directa con los exmilitantes que conforman, a partir del año 2019, un grupo de voluntarios para el trabajo de documentación es la herramienta fundamental para la clasificación y registro de las unidades documentales que dan cuerpo al archivo. 
Resulta interesante la reflexión actual del equipo acerca de cómo enfrentarse a las visiones de los voluntarios que, dada la orgánica constitutiva del movimiento, son fluctuantes y, por tanto, aparecen quiebres y diferencias en los hitos que configuran la genealogía del MIR. Entonces, ¿cómo expresamos estas fracturas en la documentación del archivo buscando no higienizar el relato? y, además, ¿todo material donado y acopiado será considerado material de archivo, $\mathrm{o}$, existen elementos que deben ser traspasados al proyecto de biblioteca de la misma fundación?

El trabajo, a la fecha, ha consistido en el reconocimiento y registro del material existente, el levantamiento y registro de memorias orales de exmilitantes, y la pesquisa de otras unidades documentales que pudieran existir tanto en el país como en el extranjero. A la par, se han realizado acciones de limpieza de las piezas y mejoría de las condiciones ambientales del recinto para su conservación.

En cuanto a la estructura orgánica de los documentos, es posible identificar materiales asociados a diversos frentes de masas, comisiones políticas y orgánicas regionales, como se puede apreciar en la ilustración 3. Si bien el esquema no representa todas las aristas de conformación del MIR, permite llegar a un consenso de constitución de relato entre quienes participaron del ejercicio de identificación documental, trascendiendo a las diferencias en cuanto a la relación con los distintos segmentos y células del MIR.

Ilustración 3: Esquema orgánico del MIR.

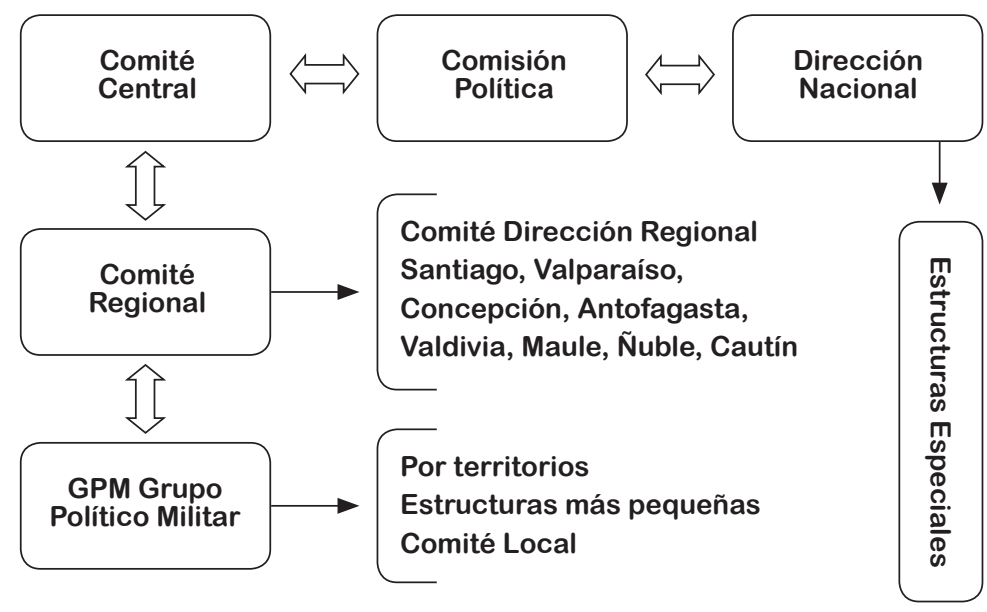

Fuente: Proyecto de creación del Archivo de la Fundación Miguel Enríquez. 
Observando esta estructura, podemos identificar jerárquicamente la información asociada a documentos fundacionales, discursos, medios de difusión, vinculados a sus principales ejes estructurales.

- Comité central: Contiene resoluciones sobre asuntos internos del MIR, declaraciones públicas, documentos de formación política para las bases partidarias.

- Comité regional: El MIR, atendiendo a la expansión de su influencia a todo Chile, crea la figura de comités regionales que son responsables de implementar la política partidaria en distintas zonas geográficas y dar cuenta de esta al Comité Central.

- Comisión política: Esta instancia superior de decisión del MIR, compuesta por siete miembros, reemplazó a la figura "Dirección Nacional o Secretariado Nacional" desde el año 1970.

Ahora bien, ya definida la orgánica de este archivo, nos enfrentamos a uno de los principales problemas que afectan las iniciativas de archivos y documentación de organizaciones sin fines de lucro, que es resguardar el material sin conocimientos técnicos y ponerlo en acceso público basado en las relaciones personales de quienes consultan los materiales. Esto significa en la práctica, que no existen protocolos de ingreso, registro, uso, etc., convirtiéndose básicamente en un repositorio de documentos que poseen un alto valor personal para quien los donó, pero que, solo potencialmente, representan un valor corporativo que obliga al registro y salvaguarda de este patrimonio institucional, y, por tanto, a la constitución de archivos que apelen a memorias institucionalizadas.

En el caso del Archivo FME, ¿nos encontramos frente a un archivo institucional y de valoración para los exmilitantes del MIR? Desde nuestra perspectiva no. Sin embargo, las múltiples voces y grupos que articulan su legado, implica tener una mirada mixta del valor nostálgico del archivo y documentos y la relación con un valor histórico social, que se entrama a un contexto mayor, un contexto fuera de lo institucional.

Nos enfrentamos aquí a una discusión entre la necesidad de configurar una historia institucional basada en uno de sus actores principales, como lo es Miguel Enríquez, pero, también, a la relevancia que alcanza la propia institución del Movimiento de Izquierda Revolucionaria. Entonces, podemos hablar de que existe un punto de partida donde la Fundación Miguel Enríquez impulsa el ejercicio de rescatar, compilar y documentar la historia del MIR desde su fundación hasta el presente. La necesidad de levantar este entramado histórico institucional radica en la invisibilización de la misma en la historia reciente 
y otorgar una mirada holística que sea capaz de aglutinar la diferencia de sus actores, de sus hitos y de sus ideas.

La fragmentación de esta historia institucional, debido a la persecución durante la dictadura y post dictadura y a la invisibilización del trabajo y aporte del MIR a la historia social y política del país, significa también el fraccionamiento de su soporte documental, el que ha sido puesto a resguardo por diversos actores testigos y partícipes del movimiento y la época. En este contexto, nos encontramos con revistas, panfletos, afiches, textos fundacionales, manuales, entre otros documentos, que volvieron desde Europa, estableciendo un acto de repatriación de la memoria.

El soporte y materialidad de la documentación es, sin duda, un campo de amplia y compleja descripción, o al menos debería serlo al momento de su indexación, pues da cuenta de la fragilidad material a la que fue expuesta en la clandestinidad. Por ejemplo, la revista El Rebelde, que pasa de ser una revista de distribución y venta a una revista de resistencia, cuyas trazas histórico-políticas se pueden observar en las tipologías de papel y tipografías diversas que hablan de la precariedad y vulnerabilidad en contexto de una dictadura cívico-militar.

Otro ejemplo claro de esto es el documento de propaganda titulado ¿Qué es el MIR? En la portada se observa, escrito a mano, un subtítulo que indica "Publicación del departamento de educación política del comité central del MIR. Diciembre 1974." Este documento tiene dos tipos de papel distinto y fue escrito con tres máquinas de escribir. Posee subrayados y anotaciones en lápiz mina.

Esto da cuenta de las medidas de seguridad del momento en tanto impresión y trabajo clandestino, pero también da cuenta de su propia historicidad; el documento se vuelve objeto y destaca no únicamente por sus contenidos, sino por la capacidad argumental de su materialidad, volviéndose un vehículo de información en sí mismo, capaz de evocar y transmitir el contexto de su producción y circulación, es decir, su genealogía e historicidad.

El desarrollo del archivo de la Fundación Miguel Enríquez aportará directamente en la difusión de información de una parte de la historia política y social de Chile, junto a ello de una forma de trabajar y organizarse políticamente en comunidad con áreas de la sociedad civil y militar que buscaron una respuesta comunitaria a los problemas sociales de la década de los 60's, 70's y 80's. (Proyecto de creación del Archivo de la Fundación Miguel Enríquez).

Esta visión desarrollada por el equipo del Archivo de la FME permite la vinculación con el ethos mayor que trasciende la historia institucional y 
se vuelca sobre la situación del país y su correlación con la historia política latinoamericana. De esta manera, la recuperación institucional es un vehículo para establecer u aportar a un metarrelato de la historia política y social del período.

En la actualidad, la fundación cuenta con aproximadamente 3.000 documentos que, desde diversas tipologías, dan cuenta de la relación histórica, social y política del MIR. En una primera etapa, el registro como inventario permite establecer el número, tipo y estado de conservación de la documentación, pero este registro básico debe ser complementado con la incorporación de una referencia asociada a la historia institucional, generando el primer eslabón en la cadena de valoración vista anteriormente (Ilustración 1).

Tabla 1: Hitos Históricos del MIR.

\begin{tabular}{|c|l|}
\hline Año & Hito Histórico \\
\hline 1965 & $\begin{array}{l}14 \text { y } 15 \text { de agosto. Se realiza el Congreso de Unidad Revolucionaria, donde } \\
\text { se funda el Movimiento de Izquierda Revolucionaria, estableciendo la } \\
\text { Declaración de Principios del MIR. }\end{array}$ \\
\hline 1967 & $\begin{array}{l}\text { Agosto. Primera división del MIR en la reunión del Comité Central, } \\
\text { encargado de organizar el III Congreso de la organización. Miguel } \\
\text { Enríquez es electo Secretario General de la organización. }\end{array}$ \\
\hline 1969 & $\begin{array}{l}\text { Junio. Segunda división del MIR. El grupo que critica la línea de } \\
\text { acercamiento a los Frentes de Masa, propuesta por la Dirección, se retira y } \\
\text { forma el Movimiento Revolucionario Manuel Rodríguez (MR-2). }\end{array}$ \\
\hline 1970 & $\begin{array}{l}\text { Septiembre. Tregua en la táctica de las acciones de propaganda armada, a } \\
\text { partir de la elección de Salvador Allende como presidente de la República, } \\
\text { el } 4 \text { de septiembre de 1970. }\end{array}$ \\
\hline 1971 & $\begin{array}{l}14 \text { de agosto. Luciano Cruz, uno de los fundadores y dirigentes del MIR, } \\
\text { muere accidentalmente. }\end{array}$ \\
\hline 1973 & $\begin{array}{l}11 \text { de septiembre. Golpe de Estado liderado por Augusto Pinochet. El MIR } \\
\text { pasa a la clandestinidad y aplica la consigna de "no asilo", para seguir } \\
\text { luchando al interior de Chile contra la dictadura. }\end{array}$ \\
\hline 1974 & $\begin{array}{l}\text { 5 de octubre. Miguel Enríquez, dirigente del MIR, muere en un } \\
\text { enfrentamiento con un grupo de la Dirección Nacional de Inteligencia } \\
\text { (DINA). }\end{array}$ \\
\hline 1978 & $\begin{array}{l}\text { Se plantea la Operación Retorno para regresar clandestinamente a Chile y } \\
\text { unirse a la resistencia contra la dictadura. Para esto los integrantes del MIR } \\
\text { deben pasar por cursos de formación militar (principalmente en Cuba). }\end{array}$ \\
\hline
\end{tabular}




\begin{tabular}{|c|l|}
\hline 1982 & $\begin{array}{l}\text { Fracaso de la Guerrilla de Neltume, que es el intento del MIR por } \\
\text { consolidar un foco guerrillero rural en la zona cordillerana de la Región de } \\
\text { Los Ríos. Es el principio del desmembramiento del MIR como orgánica. }\end{array}$ \\
\hline 1983 & $\begin{array}{l}\text { 11 de mayo, primera Protesta Nacional convocada por la Confederación de } \\
\text { Trabajadores del Cobre (CTC). Los militantes del MIR que se encuentran } \\
\text { en Chile participan activamente junto al pueblo en las calles. }\end{array}$ \\
\hline 1986 & $\begin{array}{l}\text { Diciembre. Tercera división del MIR (MIR-político / MIR- militar) en la } \\
\text { reunión que sostienen en Buenos Aires la Dirección Interior (en Chile) y la } \\
\text { Dirección Exterior (en el exilio). }\end{array}$ \\
\hline 1990 & $\begin{array}{l}\text { Se disuelven el MIR-político / MIR-militar, las dos últimas divisiones del } \\
\text { MIR. }\end{array}$ \\
\hline
\end{tabular}

Fuente: Elaboración propia. Grupo de trabajo Archivo FME.

Los hitos históricos expuestos en la Tabla 1 permiten una primera relación con la base documental del archivo y su relación con la historia institucional. A partir de esto se establecen tentativamente los siguientes fondos:

- Fondo Comité Central (1965 - 1986)

- Fondo Comisión Política (1970 - 1986)

- Fondo Secretario General (1965 - 1986)

- Fondo Dirección Nacional (1965 - 1969)

- Fondo Fracción (Post-División) 1987 - 1994

- Fondo Fundación Miguel Enríquez (2014 - actualidad)

El resguardo, la catalogación y documentación de los archivos, no busca sino ser usado y activado con un sinnúmero de usuarios, públicos o visitantes, más allá de su comunidad de origen o del colectivo que le da sentido a la producción y circulación de estos bienes documentales. La práctica de registro y documentación va más allá del mero ejercicio técnico de establecer la conservación, medir sus dimensiones y realizar una ficha que permita el reconocimiento de sus contenidos. Esta busca disponer sus materiales ante el público y a través de categorías de búsqueda en los metadatos. Por lo tanto, se desprende de la discusión, que esta historia institucional afecta a un colectivo mayor, territorial y político, desde donde miramos el acervo documental y desde donde construimos los valores patrimoniales vinculantes y relevantes en este ejercicio. En este sentido, la metadata debe ser un ejercicio más allá de la institución y más allá de los especialistas, debe estar en una constante construcción y de manera relacional con las comunidades que le dan uso y significación. 
Por ende, su significación y valoración se realiza, en tiempo presente, como un ejercicio de recomposición histórica, donde todo el proceso de trabajo de documentación, así como de las tipologías de esta, nos permite entender cómo se van desarrollando un sinnúmero de encuentros y desencuentros, por ejemplo, cómo surge o cuál es su procedencia, qué relatos están imbricados en ellos, cómo circularon y finalmente cómo fueron apropiados sus discursos y enunciados y cómo pueden serlo hoy.

Lo planteado nos acerca al análisis archivístico desde una perspectiva patrimonial, que aborda tanto el fenómeno como el bien cultural de manera simultánea. Esto nos permite aproximarnos desde múltiples veredas al objeto y sus múltiples relaciones, pues su relato no es exclusivo a los contenidos que posee un documento u objeto, sino que también a la genealogía de este, a su historicidad, y la capacidad de evocar diversos relatos.

Desde nuestra perspectiva evaluativa, el archivo en su proceso de formación busca establecer el acopio y registro de una historia institucional que se ha visto amenazada y diluida por los acontecimientos históricos del país. Sin embargo, este mismo proceso genera una concatenación o sinergia positiva con los actores y sobrevivientes que forman parte de la genealogía de estos bienes patrimoniales. Permitiendo un proceso de valoración que va más allá de las formalidades técnicas propias de la archivística.

Por lo tanto, surge la necesidad de desarrollar metadatos semánticos que se relacionen con sus comunidades de origen, pero que a su vez permitan la apropiación de los significados por otros grupos y colectividades.

\subsection{Memoria 2. La evaluación de un archivo}

Decidir realizar una evaluación a un archivo conlleva el acto de detenerse, observarse, mirar el entorno, analizar los otros trabajos y situarse en relación con el recorrido emprendido, así como en la relación con otros.

Un proceso de evaluación suele tener una mirada asociada a establecer un juicio, a someterse a la apreciación crítica de otro y por ello normalmente se prefiere evitar este escenario y generar una serie de instrumentos tautológicos que ratifican una opinión sesgada con respecto a nuestro propio trabajo.

Ser observados por otros ojos y comprender las diferencias que existen entre el dónde creemos que nos encontramos y dónde realmente nos situamos, fue el paso dado por el Centro de Documentación de la Fundación Salvador Allende. En marzo del año 2019, se solicitó realizar una evaluación diagnóstica del estado del Centro de Documentación Fundación Salvador Allende (CDFSA), con la finalidad de conocer el trabajo desarrollado en los últimos 10 años, su orientación archivística y la gestión de este. 
El CDFSA plantea en la página web de la fundación que su trabajo está relacionado con la vida y obra de Salvador Allende y la Unidad Popular, y, a su vez, señala que este se encuentra a disposición de todo público: investigadores, comunidad educativa del país y el mundo internacional. En él, se pueden encontrar videos, audios, fotografías, libros, ensayos y material de prensa, como objetos pertenecientes al presidente Salvador Allende y a su familia.

Para abordar este trabajo, se estableció una metodología descriptiva que permitiera orientar el análisis evaluativo a los procesos de registro de los diversos fondos y colecciones, documentación, conservación y gestión del CDFSA. El sentido de esta evaluación, por lo tanto, buscó definir el estado de avance en que se encuentra el centro de documentación en relación con su declaración institucional y a lo establecido por la presidenta del Directorio de la Fundación Salvador Allende (Tambutti, 2019). Estas orientaciones prácticas pueden ser implementadas en un plan de trabajo para los años 2019-2020, permitiendo reorientar la planificación del Centro de Documentación en su manejo y funcionamiento, pero también, con relación a las directrices institucionales que se han definido para este período.

El Centro de Documentación de la Fundación Salvador Allende, se constituye a partir del año 1994, con la donación y adquisición de las siguientes colecciones: Fotografías (Luis Poirot), Numismática (Hortensia Bussi), Afiches (Jaime Robottam). En el año 1995 se incorporan colecciones audiovisuales, fotográficas y textiles de orígenes diversos. Ejemplo de ello es el caso de Oscar Soto, quien dona un abrigo que fue del presidente Salvador Allende (Andrade et al.). Durante el año 2015, se desarrolló el registro de entrevistas de exministros de la UP y se digitaliza el archivo de recortes de prensa o referencias críticas (Hugo Zemelman), el cual consta de 10.000 recortes.

En la actualidad, CDFSA cuenta con aproximadamente 14.000 documentos en sus fondos y colecciones. Sin embargo, se enfrenta a problemas asociados a un crecimiento inorgánico, donde la falta de definiciones al interior del centro de documentación no permite distinguir entre qué archivos son necesarios incorporar y agregan valor al Centro de Documentación o aquellos que, tengan o no vínculos con la figura del presidente Allende, no necesariamente aportan al centro de documentación (Andrade et al.).

Desde una perspectiva histórica y documental, podemos observar que la constitución del CDFSA cumple una función de reconstrucción de una memoria fragmentada, debido a que, a partir del Golpe de Estado, la familia Allende fue víctima de un expolio sistemático de sus bienes, llevándolos a perder gran parte de las pertenencias familiares. Este origen particular y cargado de ausencias, que permitieron dar continuidad a un relato histórico de la propia familia, significó 
la creación de la Fundación y su Centro de Documentación, con la finalidad de acopiar el material disperso entre cercanos y simpatizantes al presidente Allende.

Esto lleva a que el proceso de acopio de archivos (documentos, objetos, y otros) presente un crecimiento inorgánico y disperso, carente de intencionalidad por parte del CDFSA, destacando la ausencia de los procesos de valoración del archivo y las consideraciones patrimoniales en los procesos de adquisición y donaciones recibidas. Dicho de otra forma, qué características deben tener los materiales que ingresan al centro de documentación, y con qué criterios se incorporan al acervo patrimonial del mismo.

La fundación surge con este personaje histórico, entonces se hace cargo de este legado del chicho. Más allá del presidente, movimiento popular, documentos familiares, archivo familiar, en torno a una actividad política asociada a una familia entera. (Tambutti)

De acuerdo con los procesos de entrevistas desarrolladas en el marco de la evaluación del archivo, gran parte de estos materiales, tras el Golpe de Estado, fueron ocultados en sus propias casas, llevados a embajadas, o rescatados y sacados de Chile por "Tati", ${ }_{8}^{8}$ siendo esta condición genealógica la que posee un valor patrimonial, el resguardo particular de personas vinculadas al presidente Allende y al gobierno de la Unidad Popular. Sin embargo, el proceso de registro y catalogación del archivo ha sido desarrollado bajo distintas perspectivas que han dejado fuera la historicidad y genealogía de los materiales resguardados. Esto ha determinado que el proceso de resguardo se ve inconcluso, en tanto se generan vacíos en la información que no permite visualizar y conocer el valor patrimonial de los materiales. Como consecuencia, la primera dificultad a la que se enfrenta el proceso de gestión del archivo es a la priorización y carencia de una política que defina lineamientos en la ejecución del trabajo, complejizando los criterios de búsqueda de información y las definiciones de metadatos asociados.

Por otra parte, los sistemas de catalogación utilizados responden a decisiones temporales de los encargados del archivo, en que se desarrollaron codificaciones que no necesariamente permiten una homologación con otros centros de documentación, que posean características similares en sus materiales. Como ejemplo podemos señalar que no existe una relación clara entre las múltiples copias digitales y el archivo de origen, sino más bien, se les denomina en función del proyecto que las demanda. De la misma manera,

Hija del presidente Salvador Allende. 
no existe identificación topográfica de estanterías, gavetas, planeras o cajas de conservación.

Esto genera dos nuevos problemas en relación, esta vez, a su propia declaración de dar acceso a todo público. En primer lugar, no facilita la orientación in situ con respecto a la diversidad de fondos y colecciones que son resguardados por la Fundación. Y en segundo, dificulta el acceso a una base de datos unificada que permita la búsqueda de dicha información.

Además, en la actualidad, este archivo ha configurado como parte de sus servicios, la implementación de una biblioteca especializada en vínculo con las temáticas abordadas en la documentación que protegen. Sin embargo, esta tampoco se encuentra perfilada u orientada en el material que reciben y gestionan. Entonces, ¿cuál es la pertinencia que deben tener los materiales bibliográficos que gestiona el CDFSA? Hablamos de material del período presidencial 1970 a 1973, hablamos de la carrera política del presidente Salvador Allende, hablamos de la lucha contra la dictadura de Hortensia Bussi. Sin duda, la apertura o restricción de este material es la que puede brindar un mayor alcance a una biblioteca especializada en el marco de un centro de documentación y archivo, generando una reciprocidad en los procesos investigativos asociados a los fondos custodiados por el mismo.

Como hemos señalado, la precariedad en la constitución del archivo a lo largo de su historia ha tendido a incorporar diversas experiencias en el registro y catalogación de los materiales que lo componen. Ha dirigidodo su gestión al acceso a la información como una finalidad y no un medio, es decir, los esfuerzos y miradas se focalizan en el desarrollo de mecanismos que permitan generar las condiciones de "acceso universal", dejando de lado aquellas que determinan las orientaciones que ha fijado la organización que le da origen. Por lo tanto, se han dejado fuera procesos de normalización de las bases de datos que integren sus distintos orígenes, materialidades y contenidos en la conformación de fondos y colecciones.

En el proceso de levantamiento de información, se pudo constatar que esto es recurrente en otros archivos entrevistados (Archivo Patrimonial Usach, Archivo Víctor Jara, CENFOTO, entre otros), en que la focalización de las actividades ha estado dirigida a mejorar las condiciones de acceso. Para ello, los esfuerzos técnicos de los equipos han planteado la discusión de la orientación que estos deberían tener para diversos usuarios, desde los tesauros aplicados a la interfaz web.

En este sentido, la labor se ha concentrado en el acopio de material, su ordenamiento y limpieza, medidas de conservación preventiva, registro, digitalización y acceso web. Podríamos resumir que estas acciones están siendo realizadas por 
diversos archivos en la actualidad, con la finalidad la misma para todos ellos; tener el mayor acceso posible a la documentación que se resguarda. Pero, ¿la consulta web es suficiente? ¿qué finalidades de uso tienen quienes realizan estas consultas?

En lo que pudimos observar, existen fichas para consultas específicas, pero no análisis vinculados a los accesos desde diversas plataformas web: ¿qué buscaban quienes visitaban la página y, a través de qué medios accedieron a estos? Son preguntas que quedan sin responder en este proceso, tal como las consultas en in situ que no suelen ser registradas por estos equipos, por lo que se desconoce cuantitativa y cualitativamente el uso de la información que proporcionan los archivos.

En el caso particular del CEDOC de la Fundación Salvador Allende, este suele tener consultas regulares todos los meses, aumentando su frecuencia en meses conmemorativos como en septiembre.

Al plantear la cuestión del uso, pretendemos hacer hincapié en las directrices de un archivo, pues si bien todos coinciden en el acceso a todo público, definir quién es ese público se vuelve relevante a la hora de tomar decisiones con respecto al tesauro y catálogos del material, es decir, cómo se construirán la data y la metadata del archivo, que permitan algoritmos de búsqueda eficientes, que posibiliten la observación de diversas capas de información del documento, colección o fondo, y que admitan dialogar con sus usuarios.

A partir de las observaciones realizadas, existe un sesgo en la definición de un público académico en los archivos, una orientación a la investigación, sin saber realmente si serán estos quienes tengan un mayor uso de los archivos.

Esto nos sitúa nuevamente en el acceso como medio y no como fin, pues los investigadores suelen ser quienes tienen menos dificultad para bucear en información clasificada de manera básica, mientras grupos específicos de comunidades afines necesitan mayores herramientas de mediación para acceder y aprehender los contenidos que disponen los archivos.

Con ello volvemos al origen de la discusión asociada a los aspectos misionales del archivo; en el caso del Centro de Documentación de la Fundación Salvador Allende se trata de un archivo presidencial, asociado a la vida y obra del presidente, o debería ser un archivo focalizado en el pensamiento allendista, en sus contribuciones más allá de su período presidencial, pudiendo trascender incluso la figura del mismo presidente.

\subsection{Memoria 3. La activación y valoración}

El último caso observado que configura esta unidad de análisis etnográfico nos sitúa en el universo archivístico de las artes nacionales, específicamente el 
teatro. Sabemos ya que, en los últimos 10 años, el trabajo de archivos sobre la memoria del teatro y sus creadores ha tomado fuerza en el territorio nacional, investigando acerca de los complejos mecanismos que se despliegan en los procesos escénicos en términos estéticos, artísticos y éticos y conservando materialidades que permiten superar la observación historiográfica referida inicialmente solo al mundo de la literatura.

Es el caso del Programa de Investigación y Archivos de la Escena Teatral de la Escuela de Teatro UC. Creado en el año 2000, este centro de documentación es pionero en la investigación de las materias y está dedicado a la "recopilación, conservación y catalogación del material iconográfico y audiovisual de la actividad escénica chilena en sus diferentes épocas" (www.chileescena.cl). Su corpus, que ha sido donado a la Universidad por diversos teatristas nacionales, suma a la fecha 25 mil unidades documentales compuestas por fotografías, diapositivas, negativos, videos/dvd, audios, bocetos de escenografía y vestuario, afiches y programas de mano. "Junto con aportar al rescate patrimonial de este arte, su objetivo es fomentar su conocimiento, interpretación y valoración a través de la investigación histórica, teórica y crítica". (www.chileescena.cl).

Y si bien este ha logrado convertirse en el único archivo sistematizado en el área, destacándose por su alta densidad investigativa histórica, teórica y crítica, sus directrices solo se desarrollan en la zona de confort que supone la academia. Lo cierto es que este álbum de familia no es permeable al resto de las comunidades, lo que impide que estos materiales desplieguen sus potenciales en tanto activadores de lo social. Es que, si el valor del patrimonio debe corresponder a lo que se considera importante para un grupo humano y su comunidad en particular, este patrimonio lo es en su medio directo, pero también es uno vulnerable, puesto que no ha aprendido a dialogar constante y directamente con el colectivo social que le da cuerpo, sentido y razón. Está a la vista que, por ahora, esta es una construcción de nicho que no ha sabido encontrar un espacio que lo constituya como una bisagra artístico-cultural, manteniendo su valía solo al interior del mundo académico.

Las problemáticas ya descritas levantan, entonces, preguntas en torno al ejercicio de puesta en valor de estas colecciones y fondos: ¿Cómo lograr relevar la memoria artística del teatro chileno posicionándola como un reflejo de las identidades nacionales y como una vía de reflexión, emoción y encuentro activo con nuestra historia y con nuestro devenir ciudadano? ¿Cómo poner en valor sus colecciones, no solo informándolas como un mecanismo academicista que exhiba meramente lo dramatúrgico u objetual-residual, sino que permita proyectarlas desde un pasado siempre huidizo a un presente aún huidizo para evocar la performatividad que define su memoria? 
Esta última experiencia analizada permite acercarse a una posibilidad de valorización de colecciones de archivo, que desde una configuración museotópica, impulsa la apropiación ciudadana sobre el patrimonio documental de las artes escénicas nacionales, sosteniendo que desde este ejercicio dialógico y performático inherente a la actividad teatral -pero transferible transdisciplinarmente a todo ámbito- es posible conjugar, en presente, los activos que dan carne y espíritu al teatro chileno y, por tanto, a su territorio y habitar así un locus desde el cual puedan vivificar, tanto teatristas como espectadores, la relación creatividad-sociedad-memoria.

Ahora bien, articular una propuesta de lectura crítica sobre el binomio sociedad/arte escénico es posible únicamente a través de la puesta en valor del patrimonio documental del teatro, ya que el carácter efímero que supone la práctica teatral amenaza constantemente su perdurabilidad en la memoria colectiva debido a la imposibilidad de replicarse en otro espacio-tiempo en tanto es un acto de convivio. Solo a través de la investigación de los materiales que configuran sus archivos, el teatro es rescatado de su inherente condición de fugacidad, pues, la sistematización de los objetos residuales de la creación escénica permite que el teatro vuelva a la luz, dando forma a un cuerpo perenne que trasciende las barreras del tiempo y permite estimular el propio desarrollo de este arte, a la vez que las memorias del pueblo, el conocimiento y la conciencia e identificación social.

Jacques Rancière, en El reparto de lo sensible, propone que "la política y el arte, como los saberes, construyen ficciones, es decir, reordenamientos materiales de signos e imágenes, de las relaciones entre lo que se ve y lo que se dice, entre lo que se hace y lo que se puede hacer"(39). Estos reordenamientos materiales permiten distinguir la cualidad transformadora de lo real que supone el ejercicio metafórico y metonímico del teatro, pues su performance en su valor mnésico contingente da sentido de apropiación a los valores del presente y, por tanto, el teatro y la teatralidad se vuelven actividades transformadoras de la sociedad: "Lo real es lo posible realizado, y lo posible es lo real que está en curso de transformación" (Rebolledo 8).

Entonces, si observamos el devenir de la cartografía escénica del país, es posible desprender que la historia teatral chilena es indivisible de la historia sociopolítica de la nación: desde el nacimiento de la República y por más de doscientos años, el teatro no ha querido o no ha podido alejarse de la contingencia nacional estableciendo un juego de posiciones performativas (Austin) y performáticas (Taylor) que se mueven ambivalentemente entre hegemonía y disenso, reflejando o proyectando, con su repertorio de mundos imaginados, constructos idiosincráticos de relación tiempo-espacio sostenidos en discursos 
macro y micro políticos y que buscan evocar y provocar una relectura de la sociedad y del ser humano para intentar transformar la conciencia de (su) presente y de futuro. Así, cara crítica a la construcción de Chile, es posible establecer un relato genealógico cultural y contracultural que imbrique la idiosincrasia chilena con el álbum de familia de la escena nacional.

Sin embargo, si consideramos el propio equilibrio precario en el que se desarrollan las artes escénicas nacionales y las coordenadas desde las cuales se traza la configuración de los archivos del país, parece del todo necesario proponer una salida de valoración patrimonial que responda a la performatividad de la memoria del teatro y su archivo. Esto debe hacerse desde la propia especificidad creativa de este arte de representación, llevando la idea de exposición $\mathrm{y}$, por tanto, su conocimiento y valorización, al lenguaje específico de lo teatral, para crear una diáspora museotópica que no anquilose su memoria y que irradie su valía a diversos sectores, superando los públicos fidelizados. Y es que el ejercicio de exhibir estos archivos no puede suponer simplemente la idea de contemplar nostálgicamente nuestro pasado escénico como huella indeleble de un arte de alta cultura desde una estructura decimonónica, monolítica, hegemónica, y verticalizante; sino más bien, de entenderlo como un ejercicio procesual de acceso democrático al conocimiento donde se consagra la verdadera configuración de su rol público.

Entonces, al analizar las posibilidades de musealización del oficio teatral, es posible apropiarse del concepto de museotopías latinoamericanas, las que, entendidas como "prácticas pseudoinstitucionales" (Díez Fischer 1), permiten redefinir la idea misma de museo y, por tanto, de exposición de esta tipología de colecciones: al focalizarse en las limitaciones adscritas a la institución, se puede proponer un cambio de sentido que quiebre la distopía latente para impulsar la creación de nuevas plataformas estéticas, políticas y culturales. Acceder a este formato de patrimonialización y musealización de bienes culturales de esta naturaleza, aparece como una alternativa que supone romper con el espacio de soledad que acongoja a las artes escénicas y sus archivos. Así, es posible impulsar la transformación de nuestro patrimonio para dar un salto cualitativo que abandone su posición de presentador y actúe como interrogador, pasando de ser contenedor a productor de contenidos, transformando el edificio en centro de servicios, y dejando atrás una cultura de admiración para dar paso a la cultura de la comprensión, que nos permita olvidar la pasividad para entenderse en la interactividad.

El ejercicio museotópico Usted Está Aquí, nacido en el marco del Programa de Investigación y Archivos de la Escena Teatral UC y presentado en junio de 2019 en el barrio cívico de Santiago, propuso una innovación a la hora de valorizar los archivos, generando un cruce disciplinar entre performance y 
patrimonio documental del teatro chileno. Realizado por un equipo de teatristas y estudiantes de diversas carreras de artes, ciencias sociales y humanidades, e impulsado por académicos de la Escuela de Teatro UC, ${ }^{9}$ se planteó el objetivo de revisitar la historia social y urbana, a través de un audio recorrido con características de site-specific, reconociendo la relevancia y el aporte artístico y social de Isidora Aguirre y los teatros universitarios de los años 60 como performadores políticos.

El método para desarrollar esta exposición fue de tipo inductivo, es decir, caminó desde la propia experiencia colectiva para transitar hacia la experiencia individual. Sirviéndose de elementos que la ciudad y sus personas proporcionan, se provocó "una integración a la performance de las propiedades y los significados preexistentes en un sitio dado [...] enfatizando imágenes, historias y eventos particulares que revelaron las relaciones complejas entre el hombre y el espacio físico que lo rodea" (Balme 110). Aquí, los elementos del patrimonio documental del teatro se trabajaron desde el entendido que los materiales de archivo, como elementos de no-ficción, se levantan como huellas que permiten acceder a la historia reciente en la cual se imbuye al espectador. Al trabajar desde estos pequeños fragmentos de realidad pasada y presentarlos como tal durante el recorrido, se mostró una visión crítica sobre el presente, que provocó en los asistentes discusiones sobre el futuro. Así, en este ejercicio museotópico de memoria en acto, se expuso este fragmento de patrimonio no ante la ciudadanía, sino que con ella, entendiendo a la colección del teatro chileno como promotora de lo real y lo posible, y, por tanto, transformadora de lo social.

Los actos de desobediencia son "performativos políticos donde los participantes comienzan a experimentar aquello por lo cual luchan y funcionan como mediadores evanescentes o portales que comunican al mundo existente con uno posible" (Arditi 1). Teniendo esta cita como premisa para desarrollar nuestra investigación, construimos un marco interdisciplinario histórico, social y

9 Proyecto financiado por Vicerrectoría de Investigación UC. Investigadores principales: Rodrigo Canales y Angélica Martínez. Producción: Laura de la Maza y Jonathan Aravena. Museografía y diseño: Laura Gandarillas. Asistencia de diseño: Víctor López. Asesoría Guion: Ángelo Solari. Documentación: Matías Alfaro. Gráfica: Laura Gandarillas y Franca Palavicino. Pasantes investigación: Belén Barra, Gustavo Carrasco, Rafaela Garretón, Fernanda Muñoz, Diego Ortega, Catalina Ramírez, Matías Rivas, Evaluna Valdivieso, Xabier Usabiaga. (Estudiantes UC). Actores: Juan Francisco Olea, María Fernanda Cueto, Angie Muller, Karla Merino, Marcelo Lucero, Esteban Pizarro, Mauricio Fuentes, Bárbara Donoso, Adrián Díaz, Javiera Cerda, Angélica Martínez. Voces: Carmen Barros, Mariana Loyola, Braulio Martínez. Dirección escénica: Rodrigo Canales. Curatoría: Angélica Martínez (patrimonio). 
artístico que nos permitió entender estos actos performativos a través de la labor del teatro como gestor cultural de cambio.

En este sentido, los Teatros Universitarios durante los años 60 se revelaron como un espacio de la sociedad de alto compromiso político y social, generando un efecto contagio en toda la actividad teatral del país que, con no pocas dificultades, se mantuvo activa hasta finales de la dictadura, pero que durante la transición democrática -y por efectos de la globalización y la caída del bloque socialista de finales del siglo XX-debió modificar sus modos de producción. Sin embargo, desde esta época política y de protesta, quedaron resabios en las formas de creación y producción del teatro contemporáneo.

En esta genealogía del modus operandi del teatro chileno, apreciamos a Isidora Aguirre como una pieza clave en el engranaje de los Teatros Universitarios y su encadenamiento con las estructuras de los movimientos sociales y las fuerzas políticas que se hicieron especialmente relevantes a partir de la década referida. Aguirre fue pionera en el mundo del arte y del teatro en tanto mujer, abriéndose espacio entre destacados dramaturgos que poblaban la escena teatral. Su voz fue comprendida e incorporada por los principales referentes de la escena desde sus inicios, formando parte de los movimientos teatrales de vanguardia.

De la mano de los Teatros Universitarios, Isidora Aguirre abrió la década de los 60 con el estreno de La pérgola de las flores en el Teatro Camilo Henríquez para cerrarla en el año 69 con la emblemática "Los que van quedando en el camino" en la sala Antonio Varas, retratando con sus obras a personas, elementos, calles y voces que hablaban de la autenticidad, la conciencia, la dignidad y la rebelión que se vivió en el Chile de esa época. Sesenta años después, y con el neoliberalismo ya instalado en este país de contrastes, desigual y diverso, los colectivos habitan el territorio en constante conflicto con la institucionalidad e intentan mejorar sus condiciones de vida para cumplir sus aspiraciones. Y es, desde esta insurgencia latente, que se levantó el relato que dio forma a Usted Está Aquí, que curiosa y sincrónicamente, se adelantó al estallido social de octubre 2019.

Usted Está Aquí fue una invitación a mirar los detalles, una manera de volver a ocupar el espacio público para preguntarse sobre el lugar que ocupamos y el camino que recorrimos para llegar a ese lugar. Este acontecimiento convivial (Dubatti), inspirado en la figura y obra de Isidora Aguirre para celebrar el centenario de su natalicio, sucedió en las cuadras que conectan el Teatro Camilo Henríquez y el Teatro Antonio Varas. El relato escénico implicó la creación de siete módulos-estación dentro del recorrido de tres manzanas, que fluctuó entre hacer y tener una experiencia. El espectador fue invitado a ser testigo-participante para re-vivir hechos y lugares, agitando, desde el repertorio común propuesto por los archivos del teatro (Taylor), el repertorio 
individual de experiencias y memorias, y desplegó la comunión entre los participantes de la performance.

Imagen 1: Mapa del recorrido Usted Está Aquí. 2019.

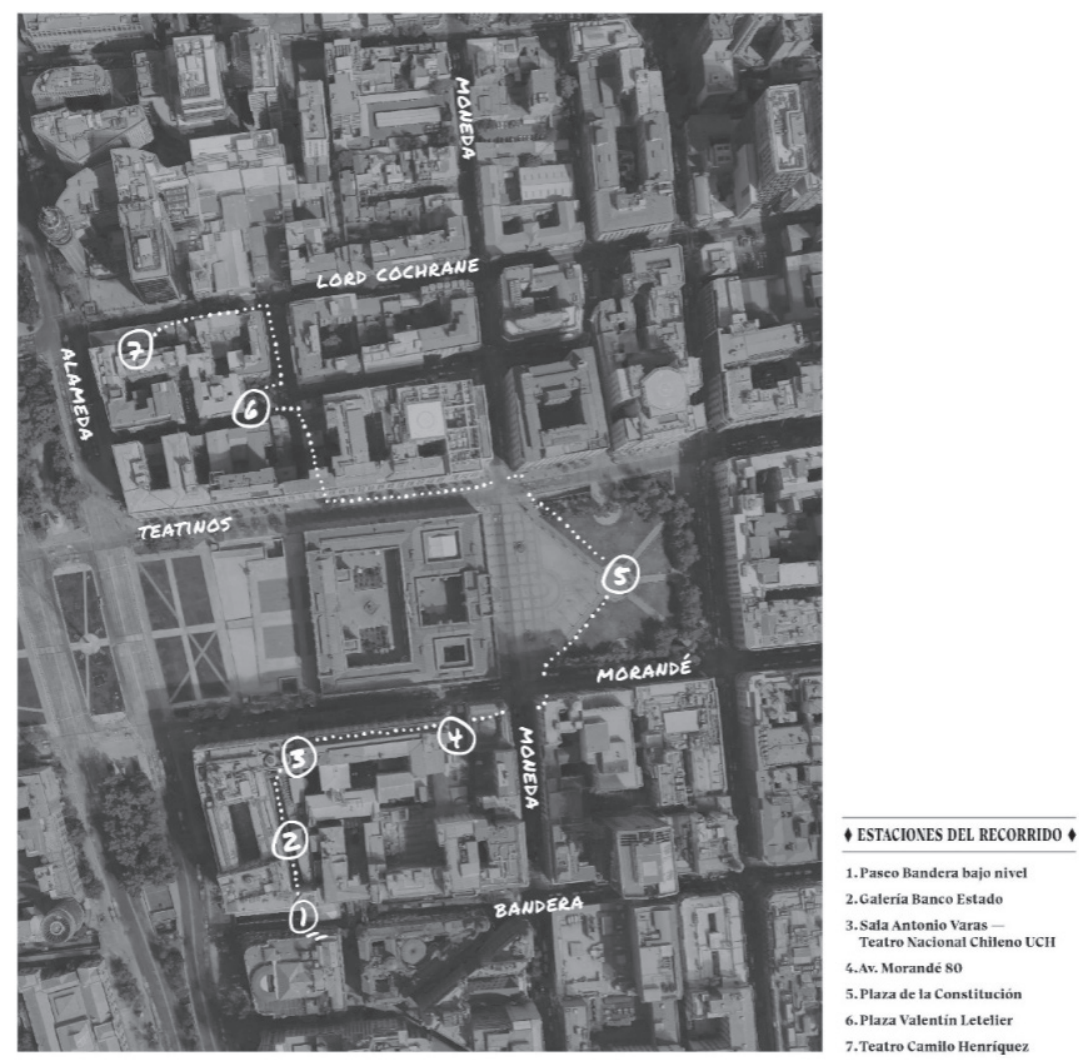

Fuente: Elaboración propia.

Optamos por el site-specific como mecanismo performático, pues nos permitía que el sujeto valorara o significara el espacio material y social habitado, potenciando así las relaciones existentes entre el acto de exponer, el artista, el participante, el teatro y el territorio urbano. La producción de este audiorecorrido, que realizó dieciséis funciones y contó con diecisiete actores y actrices que activaron cada estación del recorrido, implicó el trabajo de distrito cultural al que se sumaron importantes agentes como la Municipalidad de Santiago, el Teatro Nacional Chileno, el Teatro Camilo Henríquez y las Escuelas de Teatro $\mathrm{UC}$ y UCH. 
En la experiencia, se desplegaron más de cien unidades documentales del patrimonio teatral chileno al que aportó Aguirre. Fotografías, textos teatrales, audios, programas de mano y videos de La pérgola de las flores, Magy ante el espejo, Los que van quedando en el camino, Las pascualas, Los papeleros, El retablo de Yumbel y Diálogos de fin de siglo, y, los propios edificios teatrales articulados desde el relato biográfico de personas que trabajan y habitan este territorio, se constituyeron, durante una hora y treinta minutos, en un tejido artístico-social que tensionó el discurso macropolítico que ha latido y late en el barrio cívico de Santiago.

\section{[SE ESCUCHA VERSIÓN INSTRUMENTAL DE TONADAS DE MEDIANOCHE]}

V1: Ahora camina, hacia el poniente, deja atrás el Ministerio de Justicia y su historia.

V2: vamos a olvidar todo el sistema de justicia

V1: mira el balcón de la Moneda, por ahí se asomó Allende, y Pinochet y la selección que fue a Francia '98, y el Chino Ríos cuando fue $\mathrm{n}^{\circ} 1$. ¿Viste al Chino Ríos? ¿Te acuerdas del Chino Ríos? Levanta tu mano si te acuerdas del Chino Ríos. (Actor chino ríos cruza la plaza) Buenos tiempos para Chile, cuando se acababa el siglo XX, antes de que empezara esta locura del siglo XXI.

V2: cada siglo tiene su propia locura. El problema es que no sabemos cómo será la locura de este siglo. Aún no tenemos un golpe, ni exiliados, ni desaparecidos de este siglo. Estamos viviendo en esta democracia que en el futuro será vista como un buen tiempo para nosotros.

V1: aunque tengamos algunos muertos, algunos dirigentes que mueren de forma extraña, aunque tengamos el caso Catrillanca, y el caso Catrileo, y el caso de Macarena Valdés.

V2: aunque pensemos que es inaceptable el caso del robo de millones de los carabineros, y del ejército, y de los bancos.

V1: aunque creamos que las AFP y las ISAPRE nos roban todo, y los del papel higiénico se ponen de acuerdo

V2: pese a todo

V1: pese a todo

V2: pese a todo, estamos en democracia, y cualquiera puede intentar hacer una obra de teatro que diga lo que quiera

V1: cualquiera puede hacer una obra de arte [FIN VERSIÓN INSTRUMENTAL DE TONADAS DE MEDIANOCHE]

Extracto de audio Usted está aquí. Estación 5. 2019. 


\section{CONCLUSIÓN}

El enfoque etnográfico de este artículo nos llevó a observar la constitución de archivos y su implementación bajo una mirada de valoración nostálgica de la documentación que se protege, acumulando y resguardando objetos que poseen una relación al sentido que da origen a la organización. De este modo, se desarrolla la valoración cotidiana a objetos y documentos que pertenecieron a miembros de un colectivo determinado, dando el paso a la conformación de una historia institucional que permite ser visualizada en una escala mayor a la organización, generando posibles vínculos relacionales con el territorio, organizaciones políticas y la sociedad civil en general.

El paso siguiente para estas organizaciones es superar la historia institucional, para situar el archivo y su valor patrimonial en una escala mayor, en una dimensión que no es aislada a la organización o al territorio nacional, sino más bien se vincula a una historia política latinoamericana.

Si definiéramos los resultados etnográficos expuestos en este artículo, podríamos inferir que la constitución de un archivo conforma el primer estadio, pero que a su vez recoge las experiencias de otros centros de documentación de características similares, evitando reiterar errores que se han dado en los otros. Sin embargo, se insiste en vicios organizativos que buscan normar y comprender los documentos en función de otro más allá de la propia organización.

En este sentido y en particular el Archivo de la Fundación Miguel Enríquez, toma el concepto de "Memoria de la resistencia" para abordar el período que va entre los años 1973 y 1990. Este concepto busca reivindicar la dignidad de militantes y colaboradores que lucharon contra la dictadura cívico militar, desde sus formas de organización popular y territorial, hasta estrategias de educación política.

Es este último aspecto, el que establece una mirada relacional con otras organizaciones en el territorio nacional, ampliando su aspecto misional primigenio, a su vez la historia de movimientos de izquierda en las décadas del 60 al 90, lo sitúa bajo una perspectiva de historia política latinoamericana que puede ser una fase de mayor complejidad en la constitución del archivo.

El segundo caso aborda la mirada evaluativa después de más de una década de ejercicio, lo que conlleva una reflexión y una preocupación por los registros y su acceso. Sin embargo, los antecedentes etnográficos nos permiten inferir que este no es su principal problema, sino más bien, la redefinición de sus aspectos misionales, permitiendo desde ahí identificar futuros usos y públicos. En este sentido, podemos definir que, aun cuando este archivo se encuentra 
en una fase más avanzada que el anterior, posee la problemática de cometer errores no forzados y vicios en su operación que lo han llevado a implementar sus servicios en función de un grupo académico, pese a declarar que busca dar acceso a todo público.

Los tres archivos observados poseen una tendencia a un público académico o público de nicho, al parecer en búsqueda de alguna legitimidad o validación de estos, pero a su vez, dejan de lado su primicia de dar acceso a otros, de generar conocimiento en otros. Así, los metadatos se vuelven un fin y no un medio en los procesos de gestión de estos archivos, dejando de lado la relación con sus comunidades de origen, o los públicos que se desean alcanzar. Es así que, el paso relevante y vinculante para una buena gestión documental es la de desarrollar una política de colecciones de los archivos que permita la discriminación, crecimiento, descarte, gestión, mediación y valoración de los mismos, encontrando sentido de apropiación en la comunidad extendida.

Desde esta mirada, dos de los casos estudiados han sobredimensionado sus esfuerzos en la tecnificación de su relación con los documentos y sus posibles usuarios, pues han generado una acción en extremo conservadora de sus acervos, pretendiendo resguardar su origen prístino y no conectándolo con el presente y al alcance de los nuevos usuarios. En palabras de Foucault: "No hay que devolver el discurso a la lejana presencia del origen; hay que tratarlo en el juego de su instancia" (Foucault 39).

De los casos estudiados, el único que aborda una relación de valoración in situ es el tercer caso, que a través del proyecto Usted está aquí, se acerca a la elaboración de museotopías para enfrentar la puesta en valor de los archivos del teatro chileno, y logró ir más allá de la exposición de objetos del arte exhibidos. Además, se convierte en una invitación a elaborar un proceso participativo de construcción simbólica que, sin edificio, sin organigrama, pero con misión y potencialidades performáticas de asumir las colecciones del teatro chileno, se transformó en una herramienta activa de acción comunitaria.

El resultado de esta experiencia museotópica permitió levantar algunas conclusiones que devuelven a la sociedad su conexión con el arte escénico y que quiebran el espacio de soledad en que habitan sus memorias. Llevar el archivo a la calle:

- Resignificó el espacio urbano. En el ejercicio de recorrer el centro cívico de la capital y sus edificios teatrales subyace la idea de una cultura líquida, que otorga a los lugares un valor intrínseco no anquilosado, sino uno cambiante y en constante construcción a manos de quienes los pueblan.

- Fue un ejercicio de evocación y no de información. El material expuesto estuvo dispuesto como activador sensorial y emocional, donde el participante 
pudo completarlo con su propia historia. Se exhibió el patrimonio como una invitación, como una herramienta que la sociedad utiliza para reconstruir sus imágenes.

- Apostó por la educación experiencial. El ejercicio de reconectar los archivos con la propia especificidad de la escena y su teatralidad generaron una propuesta envolvente y vivencial que permite imaginar una relación lúdica con la experiencia museística.

- Generó autopoiesis. Comprendió la historia como algo vivo, intrahistórico, que se interpela a sí misma cada día.

- Creó una perspectiva patrimonial del teatro como generadora de identidad. Las manifestaciones escénicas fueron entendidas como elementos ligados a la identidad local, donde la comunidad pudo reconocerse en su arte y este a su vez reformularse en la comunidad.

Este ejercicio contrahegemónico y museotópico desdibujó las necesidades sobre lo museal dómino-centrista, pues el acento estuvo puesto en la vinculación sensorial con el pasado que devino en una crítica viva del presente y que permitió exponerse en la ventana a la memoria, quien se abrió ante la ciudadanía para transformar la lógica de un museo de espectadores en un espacio de actores civiles, contribuyendo a relevar las memorias artísticas y sociales del territorio. Y es justamente, a nuestro modo de ver, lo que permitirá a los archivos consagrar su fin último, que es el de conectarnos con la historia, en presente y desde su valor contingente, para comprender nuestras identidades y acceder democráticamente a la cultura.

Finalmente, diremos que los archivos estudiados buscan ser parte de una memoria colectiva, desde el prisma o particularidad que los concibe (política, arte, escena teatral, etc.), sin embargo, se centran en públicos directamente relacionados y no con nuevos usuarios o comunidades de interés. Pese a que los tres realizan actividades de mediación con organizaciones, estudiantes, académicos, éstas no son sostenidas en el tiempo y son actividades marginales con relación al desarrollo técnico que implica el archivo. Advertimos, entonces, la necesidad de descentrar los aspectos técnicos, para recuperar el sentido primigenio de los mismos, a través de diversas estrategias educacionales artísticas, escénicas, tecnológicas, entre otras y desarrollar así un acceso mediado que permita la vinculación con diversos colectivos e individuos, vinculados o no con la organización.

Este paso implicaría la recuperación de los archivos como un bien común, permitiendo su activación patrimonial de manera continua y constante por diversos miembros de la sociedad. Permitiendo la creación de metadata semántica en una relación recíproca entre comunidades de usuarios y profesionales del archivo. 
De la misma forma, este tipo de archivos está más allá del quehacer archivístico propiamente tal, por su diversidad de materiales, lo que lleva a pensar que tanto los procesos de normalización de sus bases de datos, como los procesos de valoración y activación patrimonial, necesitan una mirada transdisciplinar en la gestión de los mismos.

\section{REFERENCIAS BIBLIOGRÁFICAS}

Andrade, Pablo. Notas de Campo. 2019.

Andrade, Pablo y Leonardo Mellado. "Museología Mestiza. Dinamicidad Teórico Metodológica para enfrentar museos plurinacionales y poscoloniales". ICOFOM Study Series (journal), 2020 (en prensa).

Andrade, Pablo, et al. Informe Final Fundación Salvador Allende. Santiago, 2019.

Arditi, Benjamín. "Las Insurgencias no tienen un plan. Ellas son el plan: performativos políticos y mediadores evanescentes". Revista SulAmericana de Ciência Política, vol.1, no. 2, 2013, pp. 1-18. https://doi. org/10.22201/cieg.2594066xe.2012.46.933

Austin, John. Cómo hacer cosas con palabras. Paidós, 1998.

Balme, Christopher. Introducción a los estudios teatrales. Frontera Sur, 2013.

Conforti, Michael. Museums Past and Museums Present, vol. 14, no. 4, Great Britain, 1995.

Díez Ficher, Agustín. "El museo desde el artista: estrategias institucionales en Lima y Buenos Aires". Intervención. Revista de Conservación, Restauración y Museología, año 3, no. 5, enero-junio de 2012, pp. 5-13. https://doi.org/10.30763/intervencion.2012.5.58

Dubatti, Jorge. Introducción a los estudios teatrales. Libros de Godot, 2011.

Foucault, Michel. La arqueología del saber. Siglo XXI, 2002.

Geertz, Clifford. La interpretación de las culturas. Gedisa, 2000.

Hernández, Luis y Manuel Moro. Procedimientos de valoración documental. Acal Ediciones, 2002.

International Council on Archives (ICA). Evaluación de Documentos en Iberoamérica. 2013.

Martín-Barbero, Jesús. Oficio de Cartógrafo. Travesías latinoamericanas de la comunicación en la cultura. FCE, 2002.

Martínez, María Angélica. Notas de Campo. 2019.

Movimiento de Izquierda Revolucionaria. Declaración de Principios 15 de agosto de 1965. 15 agosto 1965. 
---. ¿Qué es el Mir? Publicación del departamento de educación política del comité central del MIR. Diciembre, 1974.

Proyecto de creación del Archivo de la Fundación Miguel Enríquez. Presentado a Iberarchivos, 2019.

Rancière, Jacques. El reparto de lo sensible. LOM, 2009

Rebolledo, Rolando. "Complejidad y azar". El búho. Revista Electrónica de la Asociación Andaluza de Filosofia, no. 11, 2013. http://elbuho.aafi.es/ buho11/rebolledo.pdf

Rivas, José. "Diálogos". Revista Electrónica de Historia, Costa Rica, 2000, pp.1-10.

Sierra, Luis. "Valoración, evaluación, selección y eliminación de similitudes y diferencias". Tercer Convivio Archivístico Nacional (Valoración Documental), Universidad de Costa Rica, 2009.

Tambutti, Marcia. Entrevista evaluación CEDOC FSA Pablo Andrade. Santiago, Marzo, 2019.

Taylor, Diana. El Archivo y el repertorio. La memoria cultural performática en las Américas. Ediciones Universidad Alberto Hurtado, 2015.

---. Performance. Asunto impreso, 2012.

UNESCO. Recomendación relativa a la protección y promoción de los museos y colecciones, su diversidad y su función en la sociedad. París, 2015.

---. Memoria del mundo directrices para la salvaguardia del patrimonio documental. París, 2002. 